\title{
Differential Expression of MicroRNA- 19b Promotes Proliferation of Cancer Stem Cells by Regulating the TSC1/mTOR Signaling Pathway in Multiple Myeloma
}

\author{
Ni Wang ${ }^{a, b} \quad$ iaohua Liang ${ }^{b} \quad$ Weijian Yu ${ }^{b}$ Shihang Zhou ${ }^{b} \quad$ Meiyun Fanga, \\ aDepartment of Hematology, the First Affiliated Hospital of Dalian Medical University, Dalian, ${ }^{\mathrm{b} B l o o d}$ \\ Typing Research Laboratory, Dalian Blood Center, Dalian, 'Department of Hematology, Affiliated \\ Zhongshan Hospital of Dalian University, Dalian, China
}

\section{Key Words}

MicroRNA-19b • Proliferation • Cancer stem cells $\cdot$ TSC1 $\cdot$ mTOR $•$ Multiple myeloma

\begin{abstract}
Background/Aims: MiR-19b has been reported to be involved in several malignancies, but its role in multiple myeloma (MM) is still unknown. The objective of this study was to explore the biological mechanism of miR-19b in the progression of MM. Methods: First, we performed real-time polymerase chain reaction (PCR) and Western blot to study the expression of miR19b, tuberous sclerosis 1 (TSC1), and caspase-3 in different groups. MTT assay was performed to explore the effect of miR-19b on survival and apoptosis of cancer stem cells (CSCs). Computation analysis and luciferase assay were utilized to confirm the interaction between miR-19b and TSC1. Results: A total of 38 participants comprising 20 subjects with MM and 18 healthy subjects as normal controls were enrolled in our study. Real-time PCR showed dramatic upregulation of miR-19b, but TSC1 was evidently suppressed in the MM group. MiR-19b overexpression substantially promoted clonogenicity and cell viability, and further inhibited apoptosis of CSCs in vitro. Furthermore, miR-19b overexpression downregulated the expression of caspase-3, which induced apoptosis. Using in silico analysis, we identified that TSC1 might be a direct downstream target of miR-19b, and this was further confirmed by luciferase assay showing that miR-19b apparently reduced the luciferase activity of wild-type TSC1 3'-UTR, but not that of mutant TSC1 3'-UTR. There was also evident decrease in TSC1 mRNA and protein in CSCs following introduction of miR-19b. Interestingly, reintroduction of TSC1 abolished the miR-19b-induced proliferation promotion and apoptosis inhibition in CSCs. Conclusion: These findings collectively suggest that miR-19b promotes cell survival and suppresses apoptosis of MM CSCs via targeting TSC1 directly, indicating that miR-19b may serve as a potential and novel therapeutic target of MM based on miRNA expression.




\section{Introduction}

Multiple myeloma (MM) is a malignant tumor of plasma cells, affecting approximately 488,200 people globally as estimated in 2015 [1]. Current understanding of the pathogenesis of MM is insufficient to develop measures to prevent it [2]. Identified risk factors are age, male sex, smoldering MM, and monoclonal gammopathy of undetermined significance (MGUS), a family history of MM or its precursor states, and African ancestry [2]. For a long time, it has been plausible that a small group of cancer stem cells (CSCs), residing in bone marrow niches, lead to the occurrence of disease relapse and refractory clones [3]. Different groups have identified a variety of CSC phenotypes in MM, such as CD138+ cells, CD19-/CD45low-/ CD38high/CD138+ cells, CD138-/CD19+ cells with cytoplasmic light chain-restricted cells, and CD138-/CD34- with memory B-cells (CD19+/CD27+) [4-7]. Some defects of CSCs are found in other pathological disorders, such as the tuberous sclerosis 1 (Tsc1) gene, the mouse double minute 2 homologue (Mdm2) gene, and deletion of Bmi1 [8-10]. Tuberous sclerosis complex (TSC) is a genetic disease caused by mutation of either the TSC1 or TSC2 gene, which code for the proteins hamartin and tuberin respectively. These proteins are the main modulators of mammalian target of rapamycin complex 1 (mTORC1). In turn, the mTOR pathway plays important roles in the regulation of cell growth, proliferation, and survival [11]. The TSC1 and TSC2 complex acts as a GTPase-activating protein for Ras homologue enriched in brain (Rheb), one of the most important upstream regulators of mTORC1. A range of upstream signaling pathways like the PI3K-Akt pathway converge at TSC1 and TSC2, but they can also modulate the activity of mTORC1. Originally, it was described that deletion of PTEN, a negative modulator of the PI3K-Akt pathway, from hematopoietic stem cells (HSCs) in adult mice enhances HSC proliferation [11].

MicroRNAs (miRNAs), a class of small endogenous non-coding RNAs, suppress the translation of specific target mRNAs to modulate gene expression. MiRNAs are associated with modulation of an array of pathological and physiological processes, such as tumorigenesis and metastasis, and they seem to be promising therapeutic targets $[12,13]$. Recently, miRNA profiles have been determined in primary patient samples and in human myeloma cell lines in a series of studies, and the pattern of miRNA expression has been related to patient survival and aberrations of specific genes [14]. Intriguingly, MM and MGUS have different expression profiles of some miRNAs, including the miR-17-92 cluster [15]. MiR-92a was the first potential biomarker found in the plasma of patients with MM, and was decreased in MM rather than in smoldering MM or MGUS [16]. A recent study has indicated that miR-16 and miR-25 are independent markers for prognosis of newly diagnosed MM [17].

Differential expression of TSC1 is also involved in the onset of MM and is associated with significant upregulation of miR-19b [18-20]. In this study, we performed in silico analysis and found miR-19b practically targeted TSC1. We predict that differential expression of miR$19 \mathrm{~b}$ triggers dysregulated TSC1 and is associated with the pathology of MM based on the above evidence.

\section{Materials and Methods}

\section{Enrollment of subjects}

A total of 38 participants comprising 20 subjects with MM and 18 healthy subjects as normal controls were enrolled in our study from the Department of Hematology, the First Affiliated Hospital of Dalian Medical University, China. The study was approved by the Ethics Committee of Dalian Medical University. Written informed consent for participation in the study was obtained from all subjects after the potential risk had been duly explained to them. All protocols for this study complied with the Declaration of Helsinki.

Multiple myeloma stem cells collection

The Magnet-based Cancer Stem Cell Isolation Kit (ProMab Biotechnologies Inc., Richmond, CA) was used to isolate stem cells according to the manufacturer's instructions. 


\section{Cellular Physiology Cell Physiol Biochem 2018;50:1804-1814 \begin{tabular}{l|l|l} 
and Biochemistry Published online: 3 November 2018 & $\begin{array}{l}\text { ○ } 2018 \text { The Author(s). Published by S. Karger AG, Basel } \\
\text { www.karger.com/cpb }\end{array}$ \\
\hline
\end{tabular}}

Wang et al.: miR-19b Promotes CSC Proliferation by Targeting TSC1

\section{RNA isolation and real-time polymerase chain reaction (PCR)}

The RNeasy Mini Kit (Qiagen, Hilden, Germany) was used to isolate total RNA from the cells in accordance with the manufacturer's instructions. RNA quality and quantity were determined using the Nanodrop spectrophotometer (Thermo Scientific Inc., Wilmington, DE) and 1.5\% (w/v) agarose gel following the standard protocol. Moloney Murine Leukemia Virus Reverse Transcriptase (Applied Biosystems, Foster City, CA) was used to reverse transcribe RNA to cDNA according to the manufacturer's instructions. The ABI 7900HT Sequence Detection System (Applied Biosystems) with SYBR-Green I (Qiagen) was used to perform real-time PCR. TSC1 primers used in the study were as follows: Sense 5'-CAACAGGCGTCTTGGTGTTG-3'; Reverse 5'-ACACACTGGCATGGAGATGG-3'. Cycle threshold (Ct) values were identified using SDS software (Applied Biosystems), the value of $2^{-\Delta \Delta \mathrm{Ct}}$ was used to describe the relative gene expression levels of TSC1 mRNA and miR-19b.

\section{Cell transfection}

Cells were cultured to $80 \%$ confluency, and then co-transfected with wild-type or mutant-type TSC1 3'-UTR vector and miR-19b mimic by electroporation using the 4D-Nucleofector X Kit (Lonza, Cologne, Germany) according to the manufacturer's protocol.

\section{Cell proliferation assay}

We used the 3-(4, 5-dimethylthiazol-2-yl)-2, 5-diphenyltetrazolium bromide (MTT) colorimetric assay (Sigma-Aldrich, CA) to assess cell proliferation as described previously [21]. All experiments were performed in triplicate independently.

\section{Clonogenic assay}

For colony formation assay, CSCs transfected with miR-19b mimic were maintained in 24-well plates at a density of 200 cells/well, and the medium was changed every 3days. After 10 days, the clones were washed with PBS, and stained with crystal violet for $5 \mathrm{~min}$. Images were captured microscopically and the clones were counted.

\section{Luciferase assay}

Pfu DNA polymerase (Fermentas, Thermo Fisher Scientific, Waltham, MA) was used to amplify the coding sequence of TSC1 containing the binding site of miR-19b. The resulting PCR products were inserted into pcDNA3.1(+), and TSC1 expression vectors were generated. We used the Quick Change Site-Directed Mutagenesis Kit (Stratagene, La Jolla, CA) to perform the site-directed mutagenesis of the 3'-UTR fragment of TSC1 combining with the miR-19b seed sequence according to the manufacturer's protocol. Luciferase assays were performed by co-transfecting MM stem cells with either reporter plasmid or Renilla luciferase vector (as control) and miR-19b mimic. MM stem cells were harvested 48h post-transfection, and the DualLuciferase Reporter Assay System (Promega, Madison, WI) was used to measure the luciferase activity. Experiments were performed in triplicate independently.

\section{Western blot analysis}

TSC1 protein was estimated by Western blot analysis. MM stem cells and tissue samples were homogenized using non-denaturing lysis buffer (Invitrogen, Carlsbad, CA) containing 1 $\mathrm{g} / \mathrm{mL}$ each aprotinin and leupeptin, $1 \mathrm{mM}$ egtazic acid, $1 \mathrm{mM}$ EDTA, $0.3 \mathrm{mM}$ phenylmethylsulfonylfluoride, $150 \mathrm{mM} \mathrm{NaCl}, 0.2 \mathrm{mM}$ sodium orthovanadate, $1 \%$ Triton X-100, $0.5 \% \mathrm{NP} 40$, and $10 \mathrm{mM}$ Tris- $\mathrm{HCl}$ (pH 7.4). Lysates were centrifuged at $10,000 \times \mathrm{g}$ for $20 \mathrm{~min}$ at $4{ }^{\circ} \mathrm{C}$. The protein concentration of the lysates was determined using a detergentcompatible protein assay kit (Pierce, Rockford, IL). Proteins in the supernatant were separated on 10\%$12 \%$ sodium dodecyl sulfate polyacrylamide gel electrophoresis and then transferred to nitrocellulose membranes. TBST $(100 \mathrm{mM} \mathrm{NaCl}, 10 \mathrm{mM}$ Tris, $0.1 \%$ Tween 20 and $5 \%$ nonfat milk powder (w/v)) was used to block the membranes for $12 \mathrm{~h}$ at $4^{\circ} \mathrm{C}$ or for $1 \mathrm{~h}$ at room temperature. Membranes were then incubated with primary antibodies against TSC1 (1:5000; Abcam, Cambridge, UK), p-S6K (1:2000; Abcam), and $\beta$-actin $\left(1: 15000\right.$; Abcam) for $12 \mathrm{~h}$ at $4^{\circ} \mathrm{C}$. Bound antibodies were then visualized using horseradish peroxidaseconjugated secondary antibodies (1:15000; Abcam). An enhanced chemiluminescence-detection system (ECL Advanced kit; Amersham Biosciences, Little Chalfont, United Kingdom) was used to detect the bound 


\section{Cellular Physiology Cell Physiol Biochem 2018;50:1804-1814 \begin{tabular}{ll|l} 
and Biochemistry Published online: 3 November 2018 & $\begin{array}{l}\text { (c) } 2018 \text { The Author(s). Published by S. Karger AG, Basel } \\
\text { www.karger.com/cpb }\end{array}$ \\
\hline
\end{tabular}}

Wang et al.: miR-19b Promotes CSC Proliferation by Targeting TSC1

antibodies. Finally, protein expression was quantified using Imaging Gauge software version 3.45. All experiments were performed in triplicate independently.

\section{Apoptosis analysis}

Cells were harvested $48 \mathrm{~h}$ after transfection and the MM stem cells were washed with PBS. FITCAnnexin V/propidium iodide Apoptosis Detection Kit (BestBio, Shanghai, China) was used to stain the cells. Flow cytometry analysis (BD FACS Canto II, BD Biosciences, San Jose, CA) was performed immediately. Each analysis was carried out in triplicate at least.

\section{Statistical analysis}

All statistical analysis was performed using SPSS software version 19.0 (SPSS Inc., Chicago, IL) and a $\mathrm{p}$ value less than 0.05 was considered to indicate statistical significance. The $\chi^{2}$ test or Student's $t$-test was used to compare variables between the experimental and control groups.

\section{Results}

\section{miR-19b expression levels in MM samples}

A total of 38 participants comprising 20 subjects with MM and 18 healthy subjects as normal controls were enrolled in our study. Using quantitative real-time PCR, we investigated the expression of miR-19b in samples from all participants. Real-time qPCR showed that miR-19b was dramatically upregulated in MM patients compared with the controls (Fig. 1), suggesting that overexpression of miR-19b induced MM tumorigenicity.

High miR-19b expression in MM CSCs line promotes cell proliferation in vitro

We estimated miR-19b expression levels in MM CSCs transfected with NC (negative control) or miR-19b mimic using real-time PCR. Briefly, electroporation was performed to transfect the MM CSCs with NC or miR-19b mimic when the cells had reached $80 \%$ confluency. miR$19 \mathrm{~b}$ mimic significantly upregulated miR-19b levels compared with NC (Fig. 2A). Based on the evident increase in miR-19b levels in cells following the introduction of miR-19b mimic,

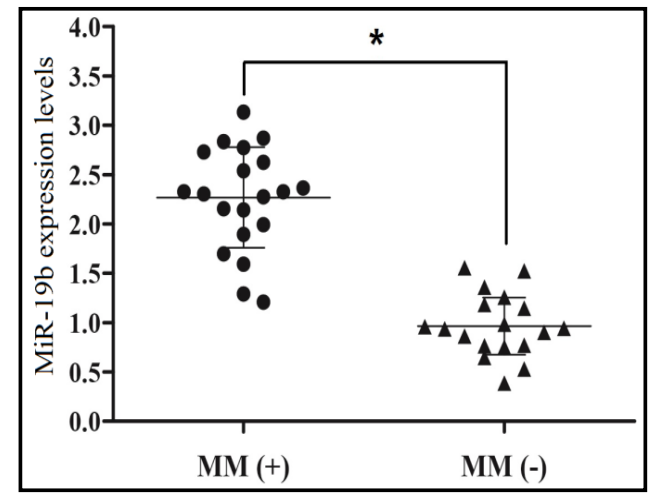

Fig. 1. Differential expression of miR-19b in MM samples and normal controls. MiR-19b was highly expressed in MM compared with MM (-) group $(\mathrm{p}<0.05)$.
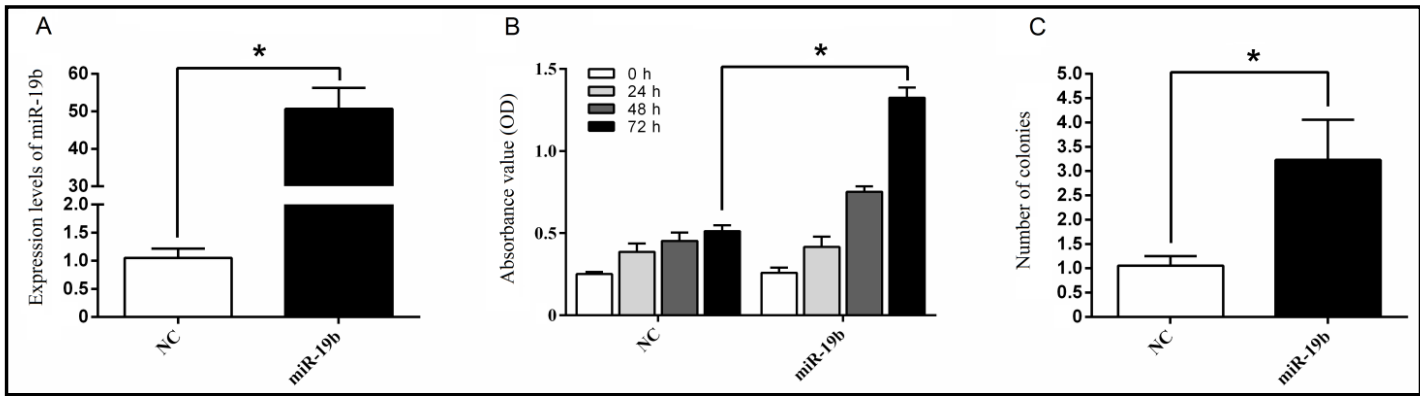

Fig. 2. Overexpression of miR-19b promotes cell proliferation in vitro. (A) MiR-19bexpression in MM CSCs was upregulated after transfection with miR-19b mimic compared with NC transfected CSCs $(\mathrm{p}<0.05)$. (B) Increased viability of CSCs transfected with miR-19b mimic compared with CSCs transfected with NC $(\mathrm{p}<0.05)$. (C) Clonogenic ability of MM CSCs transfected with miR-19b mimic was enhanced compared with NC-transfected CSCs $(\mathrm{p}<0.05)$. 
we further explored the biological function of miR-19b in MM. First, we performed MTT assay to examine the effect of miR-19b on proliferation (Fig. 2B). Cells transfected with miR$19 \mathrm{~b}$ mimic induced remarkable promotion of MM CSC survival, indicating that miR-19b overexpression enhanced proliferation of CSCs. Next, we performed a colony formation assay to confirm the above hypothesis. The assay displayed the same trend in which upregulated miR-19b remarkably promoted clonogenic ability of CSCs in comparison with NC (Fig. 2C). These data confirmed that miR-19b substantially promoted clonogenicity and cell viability.

High miR-19b expression in MM CSCs inhibits apoptosis in vitro

Annexin V/propidiumiodide (PI) staining was performed to explore the effect of miR$19 \mathrm{~b}$ on apoptosis of MM CSCs. There was an evident decrease in the apoptotic proportion of cells transfected with miR-19b mimic compared to those transfected with NC (Fig. 3A), revealing that miR-19b inhibited apoptosis of CSCs in vitro. Caspase-3 has been universally acknowledged for inducing apoptosis. Western blot analysis revealed much lower expression levels of activated caspase- 3 in the cells transfected with miR-19b compared with the NC cells (Fig. 3B). Furthermore, we quantified the ratio of activated caspase-3 to $\beta$-actin and the ratio of activated caspase- 3 to total caspase-3 as described previously [21]. Both ratios were decreased in miR-19b transfected cells compared with NC cells (Fig. 3C and 3D). This confirms that miR-19b significantly decreased activated caspase- 3 production versus the NC cells with either $\beta$-actin or total caspse- 3 as reference, suggesting that miR-19b inhibited apoptosis collectively via regulating activated caspase-3 expression levels.

Fig. 3. Inhibition of apoptosis by miR-19b overexpression. Annexin V/PI staining in CSCs transfected with miR-19b mimic or NC; miR-19b markedly inhibited apoptosis of CSCs compared with NC $(\mathrm{p}<0.05)$. (B) Western blot analysis showed reduced procaspase-3 and activated caspase-3 levels in CSCs transfected with miR19b mimic compared with NC-transfected CSCs $\quad(\mathrm{p}<0.05)$.

(C) Repressed activated caspase-3 levels in CSCs transfected with miR19b mimic compared with NC-transfected CSCs, normalized to $\beta$-actin $\quad(p<0.05) . \quad(D)$ MiR-19b significantly

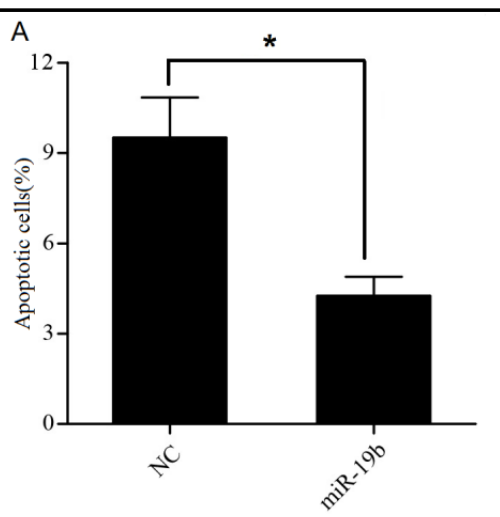

B C

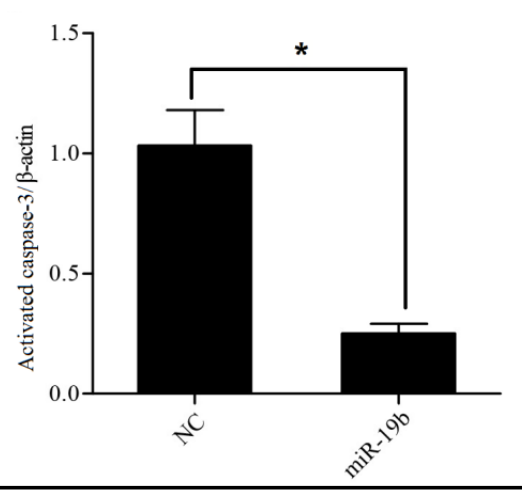

Activated caspase-3

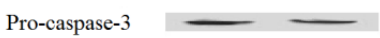

$\beta$-actin
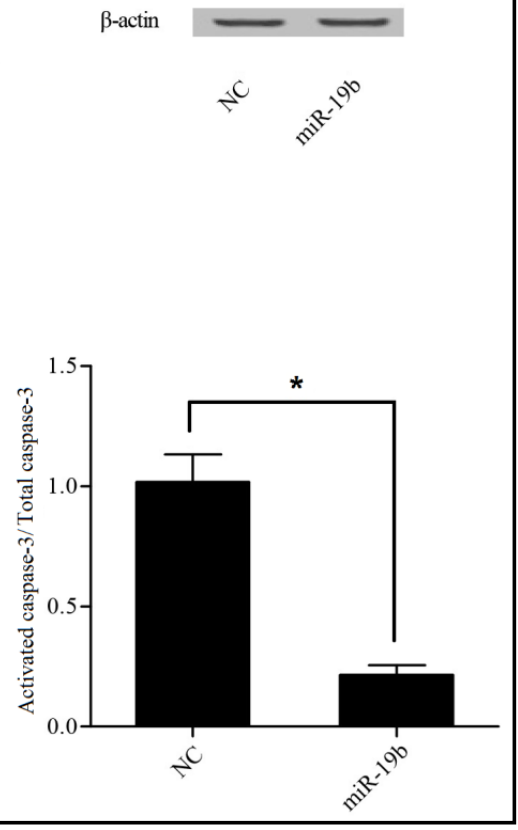

repressed activated

caspase-3 levels in comparison with NC, normalized to total caspase-3 $(\mathrm{p}<0.05)$. 
miR-19b suppresses TSC1 through targeting the 3'-UTR region of TSC1

To explore the mechanism by which miR-19b promoted proliferation and inhibited apoptosis of MM CSCs, bioinformatics databases, such as miRanda and TargetScan, were searched to identify potential targets of miR-19b. TSC1 was consequently identified as a target according to the search results of these two bioinformatics databases. The "seed sequence" in the 3'-UTR of TSC1 (Fig. 4A) was highly conserved across the species, indicating that the "seed sequence" may play an important role in human evolution. Furthermore, to confirm whether TSC1 was a direct downstream of miR-19b, we generated luciferase reporter vectors transfected with either wild-type or mutant 3'-UTR of TSC1. The Dual-Luciferase Reporter Assay System was then used to measure luciferase activity $48 \mathrm{~h}$ after transfection. MiR-19b significantly reduced luciferase activity in the cells transfected with wild-type 3'UTR of TSC1, while miR-19b had almost no effect on luciferase activity in cells transfected with mutant 3'-UTR of TSC1 (Fig. 4B). This suggested that TSC1 was a validated target of miR-19b, and that miR-19b suppressed TSC1 expression.

Fig. 4. TSC1 is a direct target of miR-19b. (A) MiR-19b directly targeted the highly conserved "seed sequence" in the TSC1 3'UTR. (B) Luciferase activity in MM CSCs transfected with luciferase reporter vector containing WT (wild-type) or MUT (mutant) TSC1 3'-UTR, along with miR-19b mimic or NC. MiR-19b significantly downregulated luciferase activity of wild-type TSC1 3'-UTR compared with $\mathrm{NC}(\mathrm{p}<0.05)$, but not that of mutant TSC1 3'-UTR.
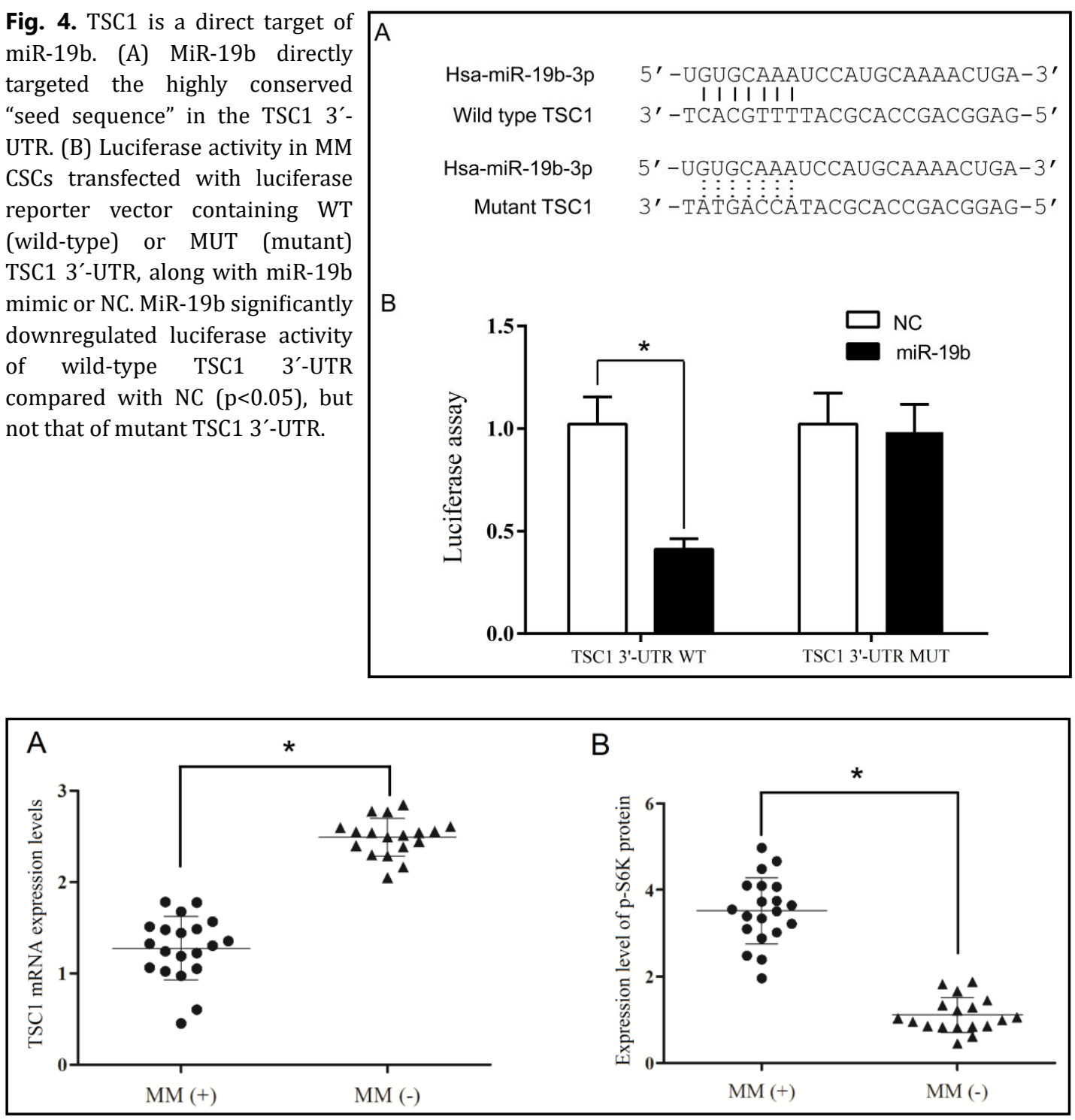

Fig. 5. Differential TSC1 mRNA and p-S6K protein expression in MM tissues and normal controls. (A) Lower TSC1 mRNA expression in MM samples compared with normal controls $(\mathrm{p}<0.05)$. (B) Higher $\mathrm{p}$-S6K protein level in MM samples compared with normal controls $(\mathrm{p}<0.05)$. 
TSC1 and $p$-S6K expression in MM samples

We examined TSC1 and p-S6K expression in 38 samples (20 subjects with MM and 18 normal controls) using quantitative reverse transcription PCR and Western blot analysis. In MM samples, mRNA levels of TSC1 (Fig. 5A) were much lower, while protein levels of p-S6K (Fig. 5B) were much higher than those in the controls, indicating that overexpression of miR$19 \mathrm{~b}$ induced tumorigenicity of MM by regulating expression of TSC1 and p-S6K.

\section{Downregulation of TSC1 inhibits MM cell proliferation and induces apoptosis in vitro}

The following results demonstrated that both TSC1 mRNA (Fig. 6A) and protein (Fig. 6B) expression levels in MM CSCs were blocked following transfection with miR-19b, showing that miR-19b reduced expression of TSC1. To explore the mechanism by which miR-19b promoted proliferation and inhibited apoptosis in MM CSCs, we performed MTT assay and cell apoptosis analysis. First, CSCs were transfected with NC plasmid or miR-19b mimic or with miR-19b mimics plus TSC1 as a rescue experiment. Cell proliferation was apparently

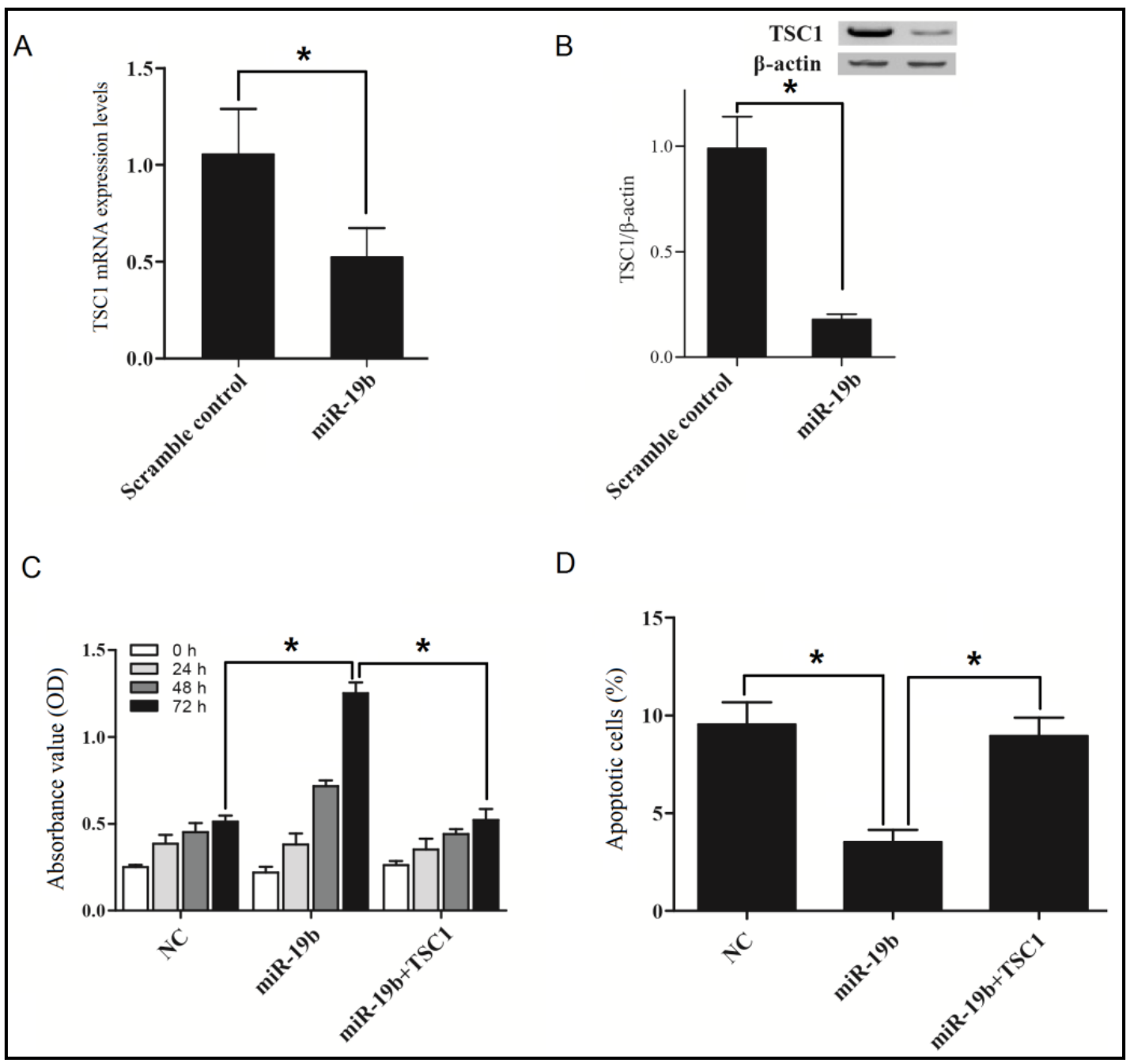

Fig. 6. (A) Decreased TSC1 mRNA levels in MM CSCs transfected with miR-19b mimic compared with NC $(p<0.05)$. (B) Decreased TSC1 protein level in MM CSCs transfected with miR-19b mimic compared with NCtransfected CSCs, normalized to $\beta$-actin ( $p<0.05$ ). (C) Viability of CSCs transfected with miR-19b mimic was promoted compared with NC-transfected CSCs $(\mathrm{p}<0.05)$, which was abolished by TSC1. (D) Apoptosis was suppressed in CSCs transfected with miR-19b mimic compared with NC-transfected CSCs ( $<<0.05)$; but this was blocked by complementing with TSC1. 
promoted in the cells transfected with miR-19b mimic compared with NC-transfected cells (Fig. 6C). Interestingly, introduction of TSC1 restored the effect of miR-19b transfection. MiR-19b mimic apparently suppressed apoptosis compared with NC plasmid (Fig. 6D). Meanwhile, inhibition of apoptosis induced by miR-19b was abrogated by overexpression of TSC1. These data validated the finding that miR-19b promoted cell proliferation and inhibited apoptosis by suppressing TSC1 expression.

\section{Discussion}

MM is essentially a malignancy characterized by proliferation of terminally differentiated plasma cells and clonal B cells. It remains incurable regardless of significant progress achieved in the biology and treatment of the condition [22]. The mechanism by which Givinostat (ITF2357), a histone deacetylase inhibitor, impacts the progression of MM may involve decreased expression of miR-19a and miR-19b, which belong to the miR-17-92 cluster localized within the MIRHG1 locus (also called C13orf25) on chromosome 13q31.3. The miR17-92 cluster has been associated with tumorigenesis in B-cell neoplasms, such as MM and other types of cancers. In fact, miR-17-92 cluster overexpression mediates hyperproliferation of B cells and autoimmune disorders, while miR-17-92 deletion results in a reduction in development and proliferation of B cells [23]. A more recent study reported a direct role of miR-19a and miR-19b in the pathogenesis of MM [24]. Moreover, MM tumor growth in nude mice can be inhibited by miR-19a and miR-19b antagonists [15]. This combined effect on the cytokine and its receptor produce the most effective suppression in IL-6 signaling. Besides the IL- 6 axis, ITF2357 regulates multiple genes associated with MM development and apoptosis, such as miR-19a and miR-19b, p21, APAF-1, FGFR3, and $c-M Y C[15,23]$. MiR$19 \mathrm{~b}$ has been reported to have a role in thrombosis, cardiovascular disorders and the aging process, and its dysregulation was observed in multiple cancers, such as cervical cancer, glioma, lung cancer, and breast cancer [25]. Some studies have indicated that miR-19b was increased in cancer cells, and it enhanced chemoresistance and proliferation, whereas other studies described its role in inhibition of migration and angiogenesis [26]. Multiple studies have shown that miR-19b acted as an oncogene in chemoresistance, migration, and cancer proliferation [27]. Nevertheless, Zhang et al. discovered that in breast cancer, miR-19b played a negative regulatory role in tissue factor expression, which is critical in tumor metastasis and angiogenesis [28]. Yin et al. discovered that miR-19b suppressed angiogenesis [29]. HIF1A was also increased following miR-19b knock-down [30]. In this study, we recruited 38 subjects, including 20 patients newly diagnosed with MM and 18 subjects without MM (normal controls). We performed real-time PCR to evaluate miR-19b expression and TSC1 in MM patients and normal controls. The results showed that miR-19b was significantly upregulated, while TSC1 was significantly downregulated in MM compared with the normal controls. We then performed RT-PCR and MTT assay to explore the effect of miR-19b on cell viability, and found that miR-19b overexpression promoted CSC proliferation.

The role of TSC1 and TSC2 in breast cancer has been investigated with an emphasis on the key role of TSC1 and TSC2 in the mTOR pathway and TSC [31]. As a heterodimer of the tumor inhibitor proteins TSC1 and TSC2, the TSC complex acts as an upstream negative modulator of mTORc1 activity [32]. If cytokines, growth factors or nutrients are present, signals mediated by receptors suppress TSC activity and active GTP-bound Rheb enhances the activity of mTORc1 by phosphorylation of mTOR at Ser2448 [33]. Recently, multiple reports have described a critical role for TSC1 in mitochondrial homeostasis, and T cell quiescence and survival [34]. Moreover, it has been demonstrated that TSC1 is critical in mast cell survival and function, antigen presentation and innate immune responses, B cell development, regulatory T cell function, anti-tumor immunity and iNKT cell anergy, terminal maturation, and effector lineage fate decisions of iNKT cells [35-39]. Others investigated the impact of TSC 1 on memory $\mathrm{CD}^{+}$response and antigen-specific primary $\mathrm{CD} 8^{+}$response, proving that mTORc1 activity is important in effector/memory lineage $\mathrm{CD}^{+}$cell division. 


\section{Cellular Physiology Cell Physiol Biochem 2018;50:1804-1814 and Biochemistry DOl: 10.1159/000494821 2018 O 2018 The Author(s). Published by S. Karger AG, Basel

Preliminary findings from a previous study indicate that TSC $1^{\text {flox/flox }}\left(\mathrm{TSC} 1^{\mathrm{f} / \mathrm{f}}\right) \mathrm{CD}-4 \mathrm{Cre}$ mice had fewer $\mathrm{CD}^{+}$cells that produce gamma interferon and fewer antigen-reactive $\mathrm{CD}^{+}$cells compared with wild-type controls in response to bacterial infection [40].

The validated specific miR-451 target of TSC1 was found to trigger activation of PIK3/ Akt/mTOR signaling in MM CSCs. As a novel anti-myeloma agent, suppressor of miR-451 increased the effectiveness of myeloma treatment by reducing MDR1 mRNA expression, decreasing clonogenicity, and inducing apoptosis [19]. In this study, we found that the apoptotic proportion of CSCs was evidently decreased in cells transfected with miR-19b. This was further confirmed by Western blot analysis which revealed reduced caspase-3 levels in cells following introduction of miR-19b. Moreover, we searched bioinformatics databases to explore the potential targets of miR-19b, and we focused on TSC1 based on the search results. Furthermore, we generated luciferase reporter vectors containing either wild-type or mutant TSC1 3 -UTR, and found that miR-19b significantly suppressed wild-type TSC1 3'-UTR luciferase activity, but not that of mutant TSC1 3'-UTR. Finally, we used real-time PCR, Western blot, and MTT assay to reveal the mechanism by which miR-19b induced cell proliferation and inhibited apoptosis. We found that both TSC1 mRNA and protein levels were downregulated subsequent to transfection with miR-19b. Also, miR-19b mimic apparently promoted cell proliferation and suppressed apoptosis; however, the effects of miR-19b could be abolished by TSC1.

\section{Conclusion}

These findings collectively suggest that miR-19b induces cell survival and suppresses apoptosis of MM CSCs by directly targeting TSC1, indicating that miR-19b could serve as a novel potential therapeutic agent in the treatment of MM.

\section{Disclosure Statement}

The authors declare to have no competing interests.

\section{References}

1 Vos T, Allen C, Arora M, Barber RM, Bhutta ZA, Brown A, Carter A, Casey DC, Charlson FJ, Chen AZ, Coggeshall M, Cornaby L, Dandona L, Dicker DJ, Dilegge T, Erskine HE, Ferrari AJ, Fitzmaurice C, Fleming T, Forouzanfar MH et al.: Global, regional, and national incidence, prevalence, and years lived with disability for 310 diseases and injuries, 1990-2015: a systematic analysis for the Global Burden of Disease Study 2015. Lancet 2016;388:1545-1602.

- Siegel R, DeSantis C, Virgo K, Stein K, Mariotto A, Smith T, Cooper D, Gansler T, Lerro C, Fedewa S, Lin C, Leach C, Cannady RS, Cho H, Scoppa S, Hachey M, Kirch R, Jemal A, Ward E: Cancer treatment and survivorship statistics, 2012. CA Cancer J Clin 2012;62:220-241.

-3 Delude C: Tumorigenesis: Testing ground for cancer stem cells. Nature 2011;480:S43-45.

4 Matsui W, Huff CA, Wang Q Malehorn MT, Barber J, Tanhehco Y, Smith BD, Civin CI, Jones RJ: Characterization of clonogenic multiple myeloma cells. Blood 2004;103:2332-2336.

-5 Nara M, Teshima K, Watanabe A, Ito M, Iwamoto K, Kitabayashi A, Kume M, Hatano Y, Takahashi N, Iida S, Sawada K, Tagawa H: Bortezomib reduces the tumorigenicity of multiple myeloma via downregulation of upregulated targets in clonogenic side population cells. PLoS One 2013;8:e56954.

6 Kim D, Park CY, Medeiros BC, Weissman IL: CD19-CD45 low/- CD38 high/CD138+ plasma cells enrich for human tumorigenic myeloma cells. Leukemia 2012;26:2530-2537.

7 Boucher K, Parquet N, Widen R, Shain K, Baz R, Alsina M, Koomen J, Anasetti C, Dalton W, Perez LE: Stemness of B-cell progenitors in multiple myeloma bone marrow. Clin Cancer Res 2012;18:6155-6168. 


\section{Cellular Physiology Cell Physiol Biochem 2018;50:1804-1814 and Biochemistry \begin{tabular}{l|l} 
DOI: 10.1159/000494821 2018 The Author(s). Published by S. Karger AG, Basel \\
(c)
\end{tabular}

8 Chen C, Liu Y, Liu R, Ikenoue T, Guan KL, Zheng P: TSC-mTOR maintains quiescence and function of hematopoietic stem cells by repressing mitochondrial biogenesis and reactive oxygen species. J Exp Med 2008;205:2397-2408.

-9 Abbas HA, Maccio DR, Coskun S, Jackson JG, Hazen AL, Sills TM, You MJ, Hirschi KK, Lozano G: Mdm2 is required for survival of hematopoietic stem cells/progenitors via dampening of ROS-induced p53 activity. Cell Stem Cell 2010;7:606-617.

10 Park IK, Qian D, Kiel M, Becker MW, Pihalja M, Weissman IL, Morrison SJ, Clarke MF: Bmi-1 is required for maintenance of adult self-renewing haematopoietic stem cells. Nature 2003;423:302-305.

-11 Yilmaz OH, Valdez R, Theisen BK, Guo W, Ferguson DO, Wu H, Morrison SJ: Pten dependence distinguishes haematopoietic stem cells from leukaemia-initiating cells. Nature 2006;441:475-482.

12 Ambros V: The functions of animal microRNAs. Nature 2004;431:350-355.

13 Amodio N, Di Martino MT, Neri A, Tagliaferri P, Tassone P: Non-coding RNA: a novel opportunity for the personalized treatment of multiple myeloma. Expert Opin Biol Ther 2013;13 Suppl 1:S125-137.

14 Chi J, Ballabio E, Chen XH, Kusec R, Taylor S, Hay D, Tramonti D, Saunders NJ, Littlewood T, Pezzella F, Boultwood J, Wainscoat JS, Hatton CS, Lawrie CH: MicroRNA expression in multiple myeloma is associated with genetic subtype, isotype and survival. Biol Direct 2011;6:23.

15 Pichiorri F, Suh SS, Ladetto M, Kuehl M, Palumbo T, Drandi D, Taccioli C, Zanesi N, Alder H, Hagan JP, Munker R, Volinia S, Boccadoro M, Garzon R, Palumbo A, Aqeilan RI, Croce CM: MicroRNAs regulate critical genes associated with multiple myeloma pathogenesis. Proc Natl Acad Sci U S A 2008;105:12885-12890.

16 Yoshizawa S, Ohyashiki JH, Ohyashiki M, Umezu T, Suzuki K, Inagaki A, Iida S, Ohyashiki K: Downregulated plasma miR-92a levels have clinical impact on multiple myeloma and related disorders. Blood Cancer J 2012;2:e53.

17 Rocci A, Hofmeister CC, Geyer S, Stiff A, Gambella M, Cascione L, Guan J, Benson DM, Efebera YA, Talabere T, Dirisala V, Smith EM, Omede P, Isaia G, De Luca L, Rossi D, Gentili S, Uccello G, Consiglio J, Ria R et al.: Circulating miRNA markers show promise as new prognosticators for multiple myeloma. Leukemia 2014;28:1922-1926.

18 Qu X, Zhao M, Wu S, Yu W, Xu J, Li J, Chen L: Circulating microRNA 483-5p as a novel biomarker for diagnosis survival prediction in multiple myeloma. Med Oncol 2014;31:219.

19 Du J, Liu S, He J, Liu X, Qu Y, Yan W, Fan J, Li R, Xi H, Fu W, Zhang C, Yang J, Hou J: MicroRNA-451 regulates stemness of side population cells via PI3K/Akt/mTOR signaling pathway in multiple myeloma. Oncotarget 2015;6:14993-15007.

-20 Yamada D, Hoshii T, Tanaka S, Hegazy AM, Kobayashi M, Tadokoro Y, Ohta K, Ueno M, Ali MA, Hirao A: Loss of Tsc1 accelerates malignant gliomagenesis when combined with oncogenic signals. J Biochem 2014;155:227-233.

21 Quent VM, Loessner D, Friis T, Reichert JC, Hutmacher DW: Discrepancies between metabolic activity and DNA content as tool to assess cell proliferation in cancer research. J Cell Mol Med 2010;14:1003-1013.

-22 Mahindra A, Hideshima T, Anderson KC: Multiple myeloma: biology of the disease. Blood Rev 2010;24 Suppl 1:S5-11.

23 Mendell JT: miRiad roles for the miR-17-92 cluster in development and disease. Cell 2008;133:217-222.

24 Ventura A, Young AG, Winslow MM, Lintault L, Meissner A, Erkeland SJ, Newman J, Bronson RT, Crowley D, Stone JR, Jaenisch R, Sharp PA, Jacks T: Targeted deletion reveals essential and overlapping functions of the miR-17 through 92 family of miRNA clusters. Cell 2008;132:875-886.

-25 Dhiraj DK, Chrysanthou E, Mallucci GR, Bushell M: miRNAs-19b, -29b-2* and -339-5p show an early and sustained up-regulation in ischemic models of stroke. PLoS One 2013;8:e83717.

26 Jia Z, Wang K, Zhang A, Wang G, Kang C, Han L, Pu P: miR-19a and miR-19b overexpression in gliomas. Pathol Oncol Res 2013;19:847-853.

27 Xu XM, Wang XB, Chen MM, Liu T, Li YX, Jia WH, Liu M, Li X, Tang H: MicroRNA-19a and -19b regulate cervical carcinoma cell proliferation and invasion by targeting CUL5. Cancer Lett 2012;322:148-158.

28 Zhang X, Yu H, Lou JR, Zheng J, Zhu H, Popescu NI, Lupu F, Lind SE, Ding WQ: MicroRNA-19 (miR-19) regulates tissue factor expression in breast cancer cells. J Biol Chem 2011;286:1429-1435.

29 Yin R, Bao W, Xing Y, Xi T, Gou S: MiR-19b-1 inhibits angiogenesis by blocking cell cycle progression of endothelial cells. Biochem Biophys Res Commun 2012;417:771-776.

30 Kaidi A, Williams AC, Paraskeva C: Interaction between beta-catenin and HIF-1 promotes cellular adaptation to hypoxia. Nat Cell Biol 2007;9:210-217. 


\section{Cellular Physiology Cell Physiol Biochem 2018;50:1804-1814 and Biochemistry $\begin{aligned} & \text { DOI: 10.1159/000494821 } \\ & \text { Published }\end{aligned}$

-31 Jiang WG, Sampson J, Martin TA, Lee-Jones L, Watkins G, Douglas-Jones A, Mokbel K, Mansel RE: Tuberin and hamartin are aberrantly expressed and linked to clinical outcome in human breast cancer: the role of promoter methylation of TSC genes. Eur J Cancer 2005;41:1628-1636.

-32 Inoki K, Li Y, Zhu T, Wu J, Guan KL: TSC2 is phosphorylated and inhibited by Akt and suppresses mTOR signalling. Nat Cell Biol 2002;4:648-657.

-33 Atherton PJ, Smith K, Etheridge T, Rankin D, Rennie MJ: Distinct anabolic signalling responses to amino acids in C2C12 skeletal muscle cells. Amino Acids 2010;38:1533-1539.

-34 O'Brien TF, Gorentla BK, Xie D, Srivatsan S, McLeod IX, He YW, Zhong XP: Regulation of T-cell survival and mitochondrial homeostasis by TSC1. Eur J Immunol 2011;41:3361-3370.

35 Shin J, Pan H, Zhong XP: Regulation of mast cell survival and function by tuberous sclerosis complex 1. Blood 2012;119:3306-3314.

36 Pan H, O’Brien TF, Wright G, Yang J, Shin J, Wright KL, Zhong XP: Critical role of the tumor suppressor tuberous sclerosis complex 1 in dendritic cell activation of CD4 T cells by promoting MHC class II expression via IRF4 and CIITA. J Immunol 2013;191:699-707.

-37 Benhamron S, Tirosh B: Direct activation of mTOR in B lymphocytes confers impairment in B-cell maturation andloss of marginal zone B cells. Eur J Immunol 2011;41:2390-2396.

38 Park Y, Jin HS, Lopez J, Elly C, Kim G, Murai M, Kronenberg M, Liu YC: TSC1 regulates the balance between effector and regulatory T cells. J Clin Invest 2013;123:5165-5178.

-39 Wu J, Yang J, Yang K, Wang H, Gorentla B, Shin J, Qiu Y, Que LG, Foster WM, Xia Z, Chi H, Zhong XP: iNKT cells require TSC1 for terminal maturation and effector lineage fate decisions. J Clin Invest 2014;124:16851698.

40 Yang K, Neale G, Green DR, He W, Chi H: The tumor suppressor Tsc1 enforces quiescence of naive T cells to promote immune homeostasis and function. Nat Immunol 2011;12:888-897. 